\title{
Apontamentos para uma história da imprensa de Mato Grosso do Sul
}

\author{
Mario Luiz FERNANDES ${ }^{1}$
}

\begin{abstract}
Resumo:
Este artigo faz um breve resgate sobre o nascimento da imprensa nos dois primeiros municípios do sul de Mato Grosso a ter jornal no último quartel do século XIX: Corumbá (1877) e Nioaque (1894); e de Campo Grande (1913), o primeiro município a ter imprensa no início do século XX. Quando da criação de Mato Grosso do Sul, desmembrado de Mato Grosso em 1977, estes municípios passaram a pertencer ao novo estado, constituindo-se assim nas três cidades pioneiras da imprensa sul-mato-grossense. Porém, para contextualizar essa trajetória, inicialmente foi abordado o nascimento da imprensa de Mato Grosso, ocorrido em 1839 em Cuiabá, a capital. Trata-se de um estudo de natureza descritiva que delineia a "certidão de nascimento" da imprensa dos principais municípios dos dois estados, na virada do século XIX para o século XX, apesar dos inúmeros obstáculos que dificultaram a implantação da imprensa na região.

Palavras-chave:
\end{abstract}

História da imprensa; História da imprensa de Mato Grosso do Sul; Imprensa de Mato Grosso do Sul.

\section{Notes for a history of press of Mato Grosso do Sul}

\begin{abstract}
:
This article provides a short review about the birth of press in the first two cities in the south of Mato Grosso to have newspapers in the last quarter of 19th century: Corumbá (1877), Nioaque (1894) and Campo Grande (1913), the first city to have press in the beginning of 20th century. When Mato Grosso do Sul was created, separated from Mato Grosso in 1977, those cities now came to belong to the new state, thus being the three pioneer cities in sul-mato-grossense press. However, to contextualize this trajectory, it was initially addressed the birth of press of Mato Grosso in 1839, in Cuiabá, the capital. It is a study of descriptive nature, which outlines the "birth certificate" of press in the main cities of the two states, in the transition of 19th century to 20th century, despite several obstacles which hindered the implantation of press in the region.
\end{abstract}

Key words:

History of the press; History of the press in Mato Grosso do Sul; Press in Mato Grosso do Sul.

\section{Apuntes para una historia de la prensa de Mato Grosso do Sul}

\begin{abstract}
Resumen:
Este artículo hace un breve rescate sobre el nacimiento de la prensa en los dos primeros municipios del sur de Mato Grosso a tener periódico en el último cuartel del siglo XIX: Corumbá (1877) y Nioaque (1894); Y de Campo Grande (1913), el primer municipio a tener prensa a principios del siglo XX. En la creación de Mato Grosso do Sul, desmembrado de Mato Grosso en 1977, estos municipios pasaron a pertenecer al nuevo estado, constituyéndose así en las tres ciudades pioneras de la prensa sur-matogrossense. Pero para contextualizar esa trayectoria, inicialmente se abordó el nacimiento de la prensa de Mato Grosso, ocurrido en 1839 en Cuiabá, la capital. Se trata de un estudio de naturaleza descriptiva que delinea el "certificado de nacimiento" de la prensa de los principales municipios de los dos estados, a finales del siglo XIX para el siglo XX, a pesar de los numerosos obstáculos que difícultaron la implantación de la prensa en la región.
\end{abstract}

\footnotetext{
${ }^{1}$ Professor associado da Universidade Federal de Mato Grosso do Sul, com atuação no Mestrado em Comunicação e no curso de graduação em Jornalismo. Possui graduação em Comunicação Social/Jornalismo pela Universidade Estadual de Ponta Grossa (1989), mestrado (2000) e doutorado (2007) em Comunicação Social pela Pontifícia Universidade Católica do Rio Grande do Sul.
} 
Palabras clave:

Historia de la prensa; Historia de la prensa de Mato Grosso do Sul; Prensa de Mato Grosso do Sul.

\section{INTRODUÇÃO}

A se considerar o atual território do estado de Mato Grosso do Sul, emancipado de Mato Grosso em 1977, a imprensa sul-mato-grossense nasceu em Corumbá, em 1877, com o jornal O Iniciador. Antes de Corumbá, no ainda Mato Grosso uno, apenas Cuiabá, a capital, tinha imprensa própria, iniciada em 1839 com o Themis Mattogrossense. Ou seja, foram necessários 38 anos para que a imprensa chegasse ao interior do estado.

Decorridos 40 anos da emancipação de Mato Grosso do Sul, ainda se impõe como desafio a elaboração de pesquisas sobre a história de sua imprensa. Fatores históricos e geográficos têm sido apontados como condicionantes para esta lacuna: a emancipação do estado ainda é recente; e a distância que separa Mato Grosso do Sul dos grandes centros políticos e econômicos do país.

A essas condicionantes pode-se acrescentar a só recente criação dos cursos de comunicação no estado: a Universidade Federal de Mato Grosso do Sul (UFMS) implantou o primeiro curso de graduação em Comunicação/Jornalismo em 1989 e o primeiro mestrado em Comunicação em 2010. O mais antigo mestrado em História é de 1999, lançado no então campus da UFMS em Dourados, e que recentemente foi transformado na Universidade Federal da Grande Dourados (UFGD). Porém, conforme Mazini (2012, p. 2), "os historiadores de MS pouco produziram sobre a história da imprensa no Estado". Assim, tanto a área de história quanto a de comunicação pouco convergiram no campo de estudos sobre a história da imprensa.

Estudos mais remotos sobre o tema apresentam basicamente relações de jornais. Outros trazem histórias pontuais de algum jornal ou da imprensa de determinado município, como Rubens de Mendonça (1963), que aborda o Estado de Mato Grosso, o primeiro jornal de Campo Grande. Pesquisas recentes têm desenvolvido análises discursivas sobre como os jornais fazem a "cobertura" de temas históricos do estado e, para contextualização do objeto analisado, fazem o perfil histórico do jornal, porém, sem o foco na sua história propriamente dita. Nestes casos, podem ser citados exemplos como Arakaki (2008) $)^{2}$, Além (2011) e Andrade (2015) ${ }^{4}$.

\footnotetext{
${ }^{2}$ Suzana Arakaki, professora de História da Universidade Estadual de Mato Grosso do Sul (UEMS), no livro Dourados: memórias e representações de 1964 (2008), analisa o golpe militar de 1964 no município
} 
Melo (2001) atribui esse atraso nas pesquisas em comunicação ao fato de que

[...] a região Centro-Oeste costuma figurar no conjunto dos episódios da nossa história como caudatária dos acontecimentos protagonizados pelos centros hegemônicos nacionais. [...] explicação é plausível, pois se trata, de um território que só foi desenvolvido tardiamente. [...] Desconsiderar o desenvolvimento tardio, as disputas territoriais, a precariedade das vias de transportes, a baixa densidade demográfica e todos os problemas socioeconômicos estudados, conduziria uma análise 'míope' das Ciências da Comunicação da região Centro-Oeste. Não podemos conceber uma análise de mídia regional que excluísse sua História e sua Geografia, visto que são exatamente estas duas áreas que mostram as características das mesmas, distinguindo-se das congêneres nacionais. (MELO, 2001 p. 15).

Em razão desse retrospecto, este estudo desenvolve alguns apontamentos sobre a história da imprensa de Mato Grosso do Sul, inserindo nesse contexto a história de seus três primeiros municípios a ter jornal: Corumbá, Nioaque e Campo Grande. A proposta de "apontamentos" enuncia aqui tratar-se de um estudo inicial, um relato em construção e a ser aprofundado em todas as suas causas e circunstâncias por estudos mais apurados que revelem a completa história da imprensa sul-mato-grossense. Por uma questão de coerência história, este estudo inicia pelo nascimento da imprensa em Mato Grosso, como forma de contextualizar o leitor sobre as origens da imprensa em Mato Grosso do Sul, já a que a história da imprensa dos dois estados é indissociável.

\section{Nascedouro da imprensa em Mato Grosso}

A imprensa de Mato Grosso nasceu por iniciativa oficial, 31 anos após o surgimento dos dois primeiros jornais brasileiros lançados em 18085. As tratativas para

de Dourados e o discurso elaborado pelo jornal local O Progresso sobre esse episódio. A obra é resultado de pesquisa no Mestrado em História pela UFGD.

${ }^{3}$ Fernando de Castro Além, na dissertação no Mestrado em História da UFGD, intitulada $O$ jornal $O$ Progresso e a dinâmica política e eleitoral em Dourados (1954, 1958 e 1962), analisa o cenário político do município naqueles pleitos eleitorais a partir dos discursos e representações veiculados por $O$ Progresso.

${ }^{4}$ Danusa Santana Andrade, mestre em Comunicação pela UFMS, desenvolveu em sua dissertação a análise de conteúdo sobre $A$ cobertura dos jornais Correio do Estado, de Campo Grande, e O Estado de Mato Grosso, de Cuiabá, na criação de Mato Grosso do Sul (2015).

5 Em $1^{\circ}$ junho de 1808, o gaúcho Hipólito José da Costa lança, em Londres, o Correio Braziliense, o primeiro jornal a circular no Brasil e com conteúdo voltado aos brasileiros, embora fosse editado na Inglaterra. A 10 de setembro do mesmo ano, a Coroa Portuguesa, em solo brasileiro, cria a Gazeta do Rio de Janeiro, o primeiro jornal impresso na colônia recém-promovida à capital do império luso-brasileiro (BAHIA, 1990). 
a instalação da primeira tipografia na província iniciaram em 1837 e culminaram em 14 de agosto de 1839, com o lançamento do semanário Themis Mattogrossense. A instalação da tipografia foi articulada pelo então presidente provincial, o jurista José Antônio Pimenta Bueno - futuro marquês de São Vicente - e contou com a participação de lideranças de vários municípios como cotistas do empreendimento. O lançamento do jornal ocorreu sob a presidência provincial de Estevão Ribeiro de Resende. Somente 38 anos depois, a imprensa chegaria ao interior da província, com o lançamento de $O$ Iniciador, em 1877, em Corumbá.

Pimenta Bueno fora empossado presidente da província em 26 de agosto de 1836 e a $1^{\circ}$ de março do ano seguinte apresentava em seu Relatório Presidencial à Assembleia Legislativa, a necessidade de implantação de uma tipografia para dar " [...] publicidade dos actos das autoridades [...], vulgarisar também o conhecimento de todos os melhoramentos que as circunstâncias da Província possam adoptar [...]" (apud JUCÁ, 1995, p. 32).

Em novo relatório, de 1838, o presidente assinala que haviam sido arrecadados 2:948\$868 em subscrições (cotas) em diferentes municípios e que a tipografia, papel e tinta foram adquiridos no Rio de Janeiro ao custo total de 1:178\$480, além de mais $722 \$ 346$ para o transporte da mesma e $800 \$ 000$ como remuneração anual para o compositor Francisco José de Melo, vindo de Goiás, para colocá-la em operação. Ainda no documento, o presidente reforça a necessidade da Tipographia Provincial para impressão das leis provinciais e

[...] redação de uma folha oficial destinada só e unicamente para transcrever e publicar todos os actos officeaes, que não exigirem segredo de Governo, da Assembléia Legislativa Provincial, das Repartições Fiscaes, das Câmaras Municipaes, dos Jurados - as participações das Autoridades Policiaes, as decisões das Juntas de Paz, finalmente [...] as Leis e actos do Governo Central que disserem respeito a esta Província. (RELATÓRIO PROVINCIAL, 1838, p. 6, apud JUCÁ, 1995, p. 36).

O nascimento da imprensa mato-grossense foi relativamente rápido se considerados os obstáculos da época, como o reduzido número de habitantes na região, o alto índice de analfabetismo, o baixo poder aquisitivo dos moradores e, principalmente, a longa distância entre a província e os grandes centros do país, como Rio de Janeiro e São Paulo. Essa mesma distância fazia com que as notícias levassem 
meses para chegar à província. Outro obstáculo era o atraso tecnológico que sofria $\mathrm{o}$ Brasil em relação aos sistemas de impressão.

Mato Grosso, juntamente com Goiás, foi desmembrado de São Paulo em 1748 e em 1821, e, como as demais capitanias, foi elevado à configuração de província. Cuiabá só se tornou capital definitiva da província em 1825 e em 1839 sua população era estimada em 12 mil habitantes (MENDONÇA, 1963). Antes de ter seu próprio jornal, as notícias mato-grossenses, os atos oficiais da província, entre outros documentos que necessitavam de publicidade, eram publicados no semanário Matutina Meyapontense, que circulou na província de Goiás entre 5 de março de 1830 e 24 de maio de 1834, no Arraial de Meyaponte (atual Pirenópolis)6. As notícias sobre Mato Grosso eram publicadas nas colunas A Província de Mato Grosso e Miscelânia Cuiabanense. Após o fechamento do jornal, Mato Grosso ficou praticamente sem divulgar seus atos por meio de jornais.

O Themis Mattogrossense circulava as quartas-feiras. Tinha quatro páginas, media 31 por 21 centímetros e era diagramado em duas colunas largas. O leitor podia adquirir exemplar avulso ao preço de 80 réis ou assinatura trimestral por 800 réis, na casa de João Alves Ferreira e Joaquim de Almeida Falcão. Sua impressão, segundo Jucá (1995, p. 28), resultou também na “[...] primeira profissão fora dos limites tradicionais do poder: a de tipógrafo [...]", o que representou "[...] uma espécie de revolução profissional, pois ocupava uma escala bem acima daqueles trabalhos manuais sem remuneração condigna".

Apesar de sua importância na publicização dos atos oficiais da província, o Themis Mattogrossense foi fechado já em meados de 1840 porque a Assembleia Legislativa, que se opunha ao presidente Estevão Ribeiro de Rezende, não votou a lei orçamentária que permitiria os gastos com a tipografia.

Os quatro próximos sucessores do jornal também tinham natureza oficial. O então presidente da província, cônego José da Silva Guimarães, reorganizou a Tipographia Provincial e lançou o Cuyabano Official, em 30 de julho de 1842. Um ano depois, o nome é mudado para $O$ Cuyabano e com este permanece até julho de 1845 . Após lacuna de dois anos sem imprensa, em 2 de julho de 1847, no governo do tenente-

6 De acordo com Zaramella (2004), a Tipografia Oliveira, de propriedade do comendador Joaquim Alves de Oliveira, "um mecenas das artes e das letras", foi a primeira montada na região Centro-Oeste do Brasil. Além de Goiás e Mato Grosso, o jornal chegava a Minas Gerais. 
coronel Ricardo José Gomes Jardim, a Tipographia Provincial lança a Gazeta Cuyabana (MENDONÇA, 1963).

Como se observa, por estarem diretamente ligados ao poder público, os primeiros jornais ficavam a mercê dos interesses dos presidentes provinciais, tendo inclusive, de tempos em tempos, a troca do próprio nome, já que em essência eram apenas variações do Themis Mattogrossnse: periódicos oficiais. Sobre a prática de um jornalismo independente, relatava a Gazeta Cuyabana em artigo de capa em 2 de junho de 1847, intitulado Parte Não Official:

[...] não temos por tanto obrigação de mexer-nos com ninguém na arena política, por que não só falta-nos para isso a necessária aptidão, como também por ser-nos inhibido pelas Leis orgânicas do estabelecimento typográphico da Província a tratar em seo jornalismo e semelhante objecto; temos pois de nos contentar em satisfazer somente aos leitores com a publicação de algumas boas idéias acerca da literatura, história, moral, religião, sciencias, artes e industria, que nos forem transmitidas por pessoas intelligentes ou que deparar-mos nos autores clássicos, e mesmo em outros jornaes, além das notícias aos melhoramentos, e tranqüilidade pública da Corte e mais Províncias do Império [...] (GAZETA CUYABANA, 2 jun. 1847, p. $1)$.

Ao final da década de 40, um novo ciclo se inicia na imprensa mato-grossense. Em 31 de agosto de 1848, o governo de João Crispiniano Soares, sob protesto dos subscritores, coloca a Tipographia Provincial em leilão e esta é arrematada por José Leite Penteado. Este passou a publicar os atos oficiais ao valor de 1:200\$000, gerando mais protestos e a venda foi anulada. O historiador Jucá (1995) assim relata o desfecho da contenda:

\footnotetext{
Enquanto corria morosamente o processo, Penteado transferiu o material a Manoel Alves Ribeiro, que o transportou para Poconé, onde estaria a salvo de qualquer medida policial. Afinal, a lei de 23 de agosto de 1851 rematou a contenda, ao revalidar a negociação. Embora adversário político dos compradores, Leverger, que a sancionou, deu as razões do seu procedimento. (JUCÁ, 1995, p. 2627).
}

Assim inicia a era da iniciativa privada na história da imprensa de Mato Grosso. A 2 de setembro de 1848 é lançado o Echo Cuiabano, contratado pelo presidente da província para publicar os atos oficiais por 1:200\$000. Porém, o jornal circula por apenas dois meses; é relançado em 23 de fevereiro de 1850, sem data precisa de seu 
fechamento definitivo. Em 3 de maio de 1857, Cuiabá ganha um novo jornal, o semanário Noticiador Cuiabano, de propriedade de José Delfino de Almeida e Companhia e editado pelo capitão Lauriano Xavier da Silva. Após cem edições, encerra as atividades em 3 de abril de 1859 .

O jornalismo de oposição ao governo provincial foi inaugurado com $A$ Imprensa de Cuyabá, em 23 de julho de 1859. Fundada pelo padre Ernesto Camilo Barreto e por João de Souza Neves, apresentava-se como "veículo político, mercantil e literário". Era redatoriada por José Jacinto de Carvalho. Apesar de oposicionista, também publicava atos oficiais da administração da província e da Assembleia Legislativa.

Para Jucá (1995), a forte oposição do jornal à administração do tenente-coronel Antônio Pedro de Alencastro foi uma revolução na imprensa mato-grossense. Tal postura editorial rendeu a prisão e deportação do padre Camilo Barreto para o Rio de Janeiro. O episódio repercutiu nacionalmente e motivou a demissão de Alencastro da presidência da província.

Conforme Zaramella (2004, p. 12-13), uma das contribuições de $A$ Imprensa de Cuyabá para a história de Mato Grosso é a edição de 9 de maio de 1865, a qual relata em detalhes "a recepção dos cuiabanos ao segundo-tenente João de Oliveira Melo que, na manhã de 30 de abril de 1865, depois de romper o cerco das tropas paraguaias, chegou à Cuiabá conduzindo 230 praças do exército, vários presos, diversos civis e grande quantidade de mulheres e crianças".

Nos primeiros vinte anos de atividades, a imprensa de Mato Grosso passou do Poder Público à iniciativa privada, mas mesmo nessa nova fase não deixou de ser patrocinada pelo primeiro. Vicejando certo grau de independência, passou à oposição acompanhando com olhar mais crítico a administração pública da província. Porém, como persiste até os dias atuais, não só a imprensa mato-grossense, mas como a de todo o país, não conseguiu se desvencilhar totalmente das amarradas que a prende aos poderes político e econômico.

A partir do $314^{\circ}$ número (19/01/1865), A Imprensa de Cuyabá passou a se chamar Boletim de Mato Grosso e, conforme Jucá (1995), entrou para a história ao reportar a retomada de Corumbá em 13 de junho de 1867, episódio que pôs fim à invasão paraguaia.

Ainda nos municípios pertencentes ao atual estado de Mato Grosso, Cáceres foi elevada à categoria de cidade em 1874. Embora não tenha localizado um único 
exemplar, nem identificado dia e mês, Rubens de Mendonça (1963) assinala que a cidade teve o primeiro jornal em 1897, com o título Progresso. Em 1898, foi lançado $O$ Atalaia, dirigido pelo advogado Mariano Ramos. O jornal A Cidade de Cáceres, de 1892, fechou o ciclo da imprensa daquele município no século XIX.

\section{Origens da imprensa em Mato Grosso do Sul}

Depois de Cuiabá, a primeira cidade do interior de Mato Grosso a ter imprensa própria foi Corumbá, importante centro político, econômico e cultural da província no século XIX. Corumbá, ao sul de Mato Grosso, integrou o estado de Mato Grosso Sul quando de sua emancipação em 1977. Assim, O Iniciador, lançado em Corumbá em 1877, é o marco inicial da imprensa de Mato Grosso do Sul. Gradativamente, a imprensa foi se disseminando por municípios que compõem o atual estado sul-matogrossense: Nioaque ( $A$ Voz do Sul - 1894), Campo Grande (O Estado de Matto Grosso 1913), Ponta Porã (Ponta Porã - 1914), Bela Vista (O Apa - 1914), Três Lagoas (Gazeta de Três Lagoas - 1915), Aquidauana (A Razão - 1917) (MENDONÇA, 1963). Observa-se que à exceção de Corumbá e Nioaque, os demais municípios passaram a ter imprensa própria somente a partir do início do século XX. Nos tópicos a seguir, é traçado o breve perfil das origens da imprensa nos três primeiros municípios de Mato Grosso do Sul a entrar na era da galáxia de Gutenberg.

\section{Corumbá}

A abertura do rio Paraguai à navegação internacional foi iniciada em 1856, mas só se efetivou após o fim da Guerra do Paraguai (12/1864-03/1870). Tropas paraguaias ocuparam cidades da província do Rio de Grande do Sul e de Mato Grosso, como Corumbá, Miranda, Coxim, Albuquerque e Nioaque. Corumbá ficou sob ocupação das tropas de Solano López de 3 de janeiro de 1865 a 3 de abril de 1868. Destroçada, a cidade teve interrompido seu ciclo de desenvolvimento (PAIS, 2016).

$\mathrm{Na}$ fase de prosperidade do pós-guerra, os comerciantes portugueses Manoel Antônio Guimarães e Silvestre Antunes Pereira da Serra lançaram O Iniciador em 18 de janeiro de 1877. O semanário "comercial, noticioso e literário" trazia sob o título a epígrafe "Legalidade, Justiça, Ordem e Liberdade". Tinha quatro páginas e era impresso na tipografia que pertencera ao Themis Mattogrossense, de Cuiabá. Naquele ano, a cidade contava com três praças, dez ruas retas e sua população era de aproximadamente 
6 mil habitantes (JUCÁ, 1986). Ao final do século XIX, seu porto fluvial já era o terceiro maior da América Latina, com movimento de vapores entre o Brasil e a Europa como canal de exportação, principalmente de peles e charque para o Velho Continente.

É nesse contexto desenvolvimentista que a imprensa de Corumbá floresce. Em $1^{\circ}$ de janeiro de 1880 , é publicada A Opinião, possivelmente seu segundo periódico. O semanário "literário e noticioso" era dirigido pelo advogado Amâncio Pulquérito7. A 25 de julho do mesmo ano, segundo Rubens de Mendonça (1963, p. 32), entra em circulação $O$ Corumbaense8, "órgão de interesses do comércio, da lavoura e da instrução popular”. Bissemanário propriedade de uma sociedade anônima, o jornal era dirigido por Generoso Nunes Nogueira e tinha como editor André Troiano da Rocha Passos.

Como demonstração de seu vigoroso desenvolvimento, até o final do século XIX Corumbá publicou pelo menos os seguintes jornais, conforme listagem elaborada por Rubens de Mendonça (1963): Gazeta Liberal (1884), O Embrião (1891), Eco do Povo (1893), A Federação (1896), O Sertanejo (1897) e A Pátria (1899). Outra listagem elaborada por Estevão de Mendonça (1975), em 1908, traz ainda outros jornais: Calabrote (1882), Athleta (1882), Diabinho (1884), Oasis (1887), O Tiradentes (1897), A Violeta (1899), Município de Corumbá (1899).

\section{Nioaque}

Nioaque foi elevado à categoria de município em 18 de julho de 1890, por decreto do governador Antônio Maria Coelho. Dias depois, em 27 de julho, era criado o Partido Republicano em Cuiabá. O primeiro censo demográfico de Nioaque, em 1891, assinala que o município contava com 2.928 habitantes. Em 27 de outubro de 1892, eram eleitos o primeiro intendente, João Luiz da Fonseca e Moraes, e os membros da Câmara de Vereadores (DALMOLIN, 2016a) ${ }^{9}$.

7 A data de surgimento de A Opinião é controversa: Rubens de Mendonça (1963) assinala 1880, corroborando com Estevão de Mendonça (1975) em seu livro Datas Matogrossenses; Sônia Zaramella (2004) cita o ano de 1878; Pedro Ivo Rostey, em seu estudo Fundação de Corumbá e atas da cidade de Corumbá, aponta o ano de 1879. Zaramella (2004) informa ainda que no mesmo ano de 1878 também surgiu o jornal $A$ Tesoura, que se intitulava de "completa neutralidade na luta dos partidos políticos". Com linhas editoriais diferentes, A Opinião e $A$ Tesoura, segundo a autora, disputavam a publicidade oficial (ZARAMELLA, 2004, p. 17).

8 Rostey, no livro já citado, informa que $O$ Corumbaense foi fundado em 24 de julho de 1881 .

${ }^{9}$ Os vereadores eleitos em 27 de outubro de 1892 para o triênio 1893 a 1896 foram: João Ferreira Mascarenhas, Domingos Martins Barboza, Vicente Anastácio, José Antônio Gonçalves Teixeira e Pedro Ponce (DALMOLIN, 2016a). 
Até 1899, o sul de Mato Grosso tinha apenas cinco municípios: Corumbá, Miranda, Paranaíba, Coxim e Nioaque; este último era uma das principais potências econômicas do estado, porém, o retorno financeiro que recebia da capital, Cuiabá, era irrisório.

As únicas relações entre Nioaque [...] com Cuiabá era tão somente política e administrativa. As principais fontes geradoras de receitas do tesouro provinham das atividades econômicas do Sul. Entretanto, no momento de usufruir dos benefícios do tesouro, estes eram desviados para rumos diversos, menos para a região fonte geradora. (DALMOLIN, 2016a).

Ainda conforme Dalmolin (2016a), Nioaque era a cidade mais importante do sul politicamente, uma das maiores do estado e "precisava de um instrumento que chegasse a todos os rincões do Apa ao Paraná [rios], levando sua mensagem de positivismo, progresso, liberdade, fraternidade e união do sul mato-grossense".

Em decorrência dessa efervescência política, foi lançado em 26 de outubro de 1894 o semanário A Voz do Sul, o primeiro jornal de Nioaque, segundo município do interior do atual Mato Grosso do Sul a ter imprensa. O periódico foi iniciativa de lideranças republicanas locais e, possivelmente, com auxílio da maçonaria. O vereador e advogado republicano Cláudio Gomes da Silva instalou a primeira tipografia da cidade e nela era impresso $A$ Voz do Sul. O impressor era também o redator. O material tipográfico foi adquirido do jornal D'A Situação, de Cuiabá, pelo deputado estadual e republicano João Ferreira Mascarenhas (DALMOLIN, 2016b).

Dalmolin (2016b) enfatiza que, "inegavelmente", o primeiro instrumento político que o sul de Mato Grosso criou para defender a região foi $A$ Voz do Sul.

O próprio título $A V o z$ do Sul é uma mensagem aberta, clara, objetiva, apelativa e declarativa que os Republicanos radicados em Nioaque e nas pessoas do Coronel João Ferreira Mascarenhas, João Luiz da Fonseca e Moraes e Dr. Cláudio Gomes empregaram para defender os interesses e ideais dos habitantes do Sul. (DALMOLIN, 2016b).

O jornal tinha como proprietário João Ferreira de Mascarenhas (coronel Jango Mascarenhas), vereador e presidente do Partido Republicano de Nioaque. Ele foi o candidato a vereador mais votado em 1893 e em 1894 foi eleito deputado estadual ${ }^{10}$. O

\footnotetext{
${ }^{10}$ Mascarenhas foi uma importante liderança política do sul de Mato Grosso; em 1892, aos 28 anos, foi intendente (prefeito) de Nioaque e em 1899 foi eleito vice-governador do estado. Em razão do seu ativismo politico, em 1901 teve que se refugiar no Paraguai; quando retornou foi perseguido pelas forças
} 
periódico apresentava-se como defensor da moral e pugnava "trabalhar pelo engrandecimento da pátria mato-grossense [...]" (DALMOLIN, 2016b). Alinhado ao ideal republicano, assim se definia em seu artigo de apresentação:

Republicanos de princípios, para nós a República é a chave que coroa a abóboda desse grande edifício de conquistas político-sociais.

Que a República é o único governo que pode fazer a felicidade do Povo Brasileiro: eis as nossas convicções.

Trabalhar pelo engrandecimento da Pátria mato-grossense em todo terreno; defender os interesses estaduais, nas questões dos interesses gerais batermo-nos pelos interesses do Sul, em todas as questões em que for desenvolvido. Eis o nosso programa! (A VOZ DO SUL, 26 out. 1894, p. 1, apud DALMOLIN, 2016b).

Conforme Pais (2016), o "projeto político audacioso que foi, logo, fortemente, combatido pelos líderes mais representativos de Cuiabá, faz com que $A$ Voz do Sul tivesse vida curta". Foi empastelado em 1896, conforme Rubens de Mendonça (1963), por um cidadão conhecido por Onça Preta, que jogou o material tipográfico no rio Nioaque.

\section{Campo Grande}

A ferrovia da Noroeste só chegaria à vila em 1914 e a energia elétrica, em 1918, mas a 22 de junho de 1913, quando contava com apenas quase dois mil habitantes, a então Vila de Santo Antônio de Campo Grande de Vacaria (atual Campo Grande) entrava na era da imprensa. O primeiro jornal da futura capital do futuro estado de Mato Grosso do Sul foi uma iniciativa do advogado pernambucano Arlindo Gomes de Andrade. Com comércio diversificado e a presença de profissionais como advogados e médicos, a vila já se pronunciava como um centro regional do sul de Mato Grosso, consolidando-se 64 anos depois como a capital do novo estado (RODRIGUES, 1976).

Apesar da vertente de progresso, era precário o sistema de comunicação na vila, devido principalmente às longas distâncias, o que levou Gomes de Andrade a fundar $O$ Estado de Matto Grosso. O advogado-jornalista fora o primeiro juiz de Direito da vila e o $16^{\circ}$ intendente (01/01/1921 a 31/12/1923) do agora município. O jornal iniciou como quinzenal e depois passou a semanal, com quatro páginas, e media 32 por 44 centímetros. Era diagramado em seis colunas. Impresso em papel couchê e com letras douradas na capa, a primeira edição apresentava elevado grau de sofisticação. A

legalistas. Sua tropa foi dizimada e ele foi morto em 21/10/1901, aos 37 anos, na fazenda Esperança, às margens do rio Taquarussu, em Nioaque. (PAIS, 2016). 
Livraria, Tipografia e Papelaria da Andrade, Salles \& Irmão era a responsável pela composição e impressão (RODRIGUES, 1976).

O Estado trazia na primeira página artigo de fundo (editorial), anúncios de um médico e três advogados, além de pequena nota explicativa sobre o atraso de equipamentos de impressão que viriam da Alemanha e permitiriam a impressão do jornal em tamanho maior. Justificava ainda que seria criada uma coluna de notas telegráficas assim que fosse estabelecido o serviço de telégrafo entre a Noroeste com o restante do país. Na página dois, uma coluna de notas; na três, o balancete da Câmara Municipal de Campo Grande; a quatro era repleta de anúncios.

Segundo Rodrigues (1976, p. 12), o jornal "[...] foi recebido com entusiasmo pela população. Os seus comentários, notícias e anúncios foram 'devorados' pelos poucos leitores de então". Ao que tudo indica, não eram vendidos exemplares avulsos, pois na capa consta apenas os preços das assinaturas trimestral (8 mil réis), semestral (15 mil réis) e anual (24 mil réis).

Ao contrário do usual na época, o jornal não trazia seu programa de apresentação. Dizia não defender "este ou aquele partido", pois "não há governo bom ou mau, inteiramente"; não ser "federalista nem unitarista, presidencialista nem parlamentarista”. Assinalava não ser político porque "o jornal político é um jornal injusto". Pontuava não ter um programa definido, pois "um programa é uma mentira. Até hoje nenhum jornal cumpriu o programa que se traçou". E sentenciava: "Se nos exigirem um programa [...]. Seremos tudo. O Jornal deve ser uma grande bandeira capaz de proteger todas as boas ideias. Emparedar-se é que não" (O ESTADO DE MATO GROSSO, jun. 1913, p. 1).

Em pouco mais de um ano e meio, além do pioneirismo, um dos seus méritos históricos foi o registro da construção da Estrada de Ferro Noroeste do Brasil, que ligou São Paulo ao sul de Mato Grosso (Campo Grande) e posteriormente a Corumbá, na divisa com a Bolívia.

O tom crítico do jornal se inseriu já na primeira edição ao reclamar da morosidade nas obras de ferrovia e ao denunciar as precárias condições dos serviços dos Correios de Mato Grosso, para o jornal, o "mais relaxado" do mundo. Atento às etapas de execução da obra, registrou o momento da junção dos trilhos nas seções opostas de Campo Grande e Rio Pardo, nas proximidades do córrego Taveira, ocorrida em 31 de agosto de 1913. 
Encontravam-se no local os drs. Carlos Euler, Assis Ribeiro, Lisânias Leite, Bittencourt Sampaio, Martins Costa, Oscar Guimarães, Canguçu e muitas outras pessoas gradas.

Ao enfrentarem-se, as duas turmas romperam em vivas e gritos, continuando o resto do serviço entre uma alegria estrondosa.

Ao estrugir dos foguetes foram colocados os dois últimos trilhos, cortados pela turma do Rio Pardo.

$\mathrm{O}$ dr. Oscar Guimarães batizou à champanhe os dois pedaços de ferro que, pousando acima da corrente límpida do córrego da ligação, acabaram com a distância da nossa terra. O dr. Martins Costa apertou os parafusos.

Em seguida a máquina 14, dos serviços do Rio Pardo, atravessou o pontilhão recém-acabado. (O ESTADO DE MATO GROSSO, set. 1913, p. 2).

Outro registro foi a chegada da ferrovia a Campo Grande em 28 de maio de 1914, na seção de Porto Esperança, quando os habitantes ouviram o silvo da locomotiva pela primeira vez. $O$ Estado celebrou o acontecimento, mas não deixou de expressar um tom crítico.

\footnotetext{
O povo parecia haver cansado de esperá-la todo mês, toda semana, todo dia.

Mas, afinal chegou. Uma locomotiva já desceu a encosta e acordou os habitantes, a silvar.

Outras têm vindo, alegremente, na faina ciclópica da grande obra nacional. Todo mundo alegrou-se nesse bendito rincão brasileiro.

Aos operários cobertos de poeira, misturam-se os habitantes da cidade. São gregos, italianos, japoneses, portugueses e brasileiros de toda casta.

No local da futura estação, grupos de famílias, rapazes, velhos e crianças, irmanam-se com os homens que fazem o caminho do progresso. (O ESTADO DE MATO GROSSO, jun. 1914, p. 2).
}

A Estrada de Ferro Noroeste do Brasil foi inaugurada em 14 de outubro de 1914 e se constituiu na principal promotora do desenvolvimento do sul de Mato Grosso no século XX. Naquela manhã festiva, a comitiva do governo federal composta Carlos Euler (representando o ministro da Viação), coronel José Bevilácqua (representando o ministro da Guerra), senador Antônio Azeredo, general Caetano de Albuquerque, deputado A. de Mavignier, entre outras autoridades, foi recebida em Rio Pardo pelo intendente municipal de Campo Grande, José Santiago e lideranças locais. Na comitiva, O Estado registra também a participação da imprensa nacional e internacional, como C.

S. Rutlindg (representante do Times), Dario de Mendonça (do Jornal do Commercio), 
Macedo Soares (do Imparcial), Silvino Cardoso (da Época) entre outros cujos nomes não são mencionados. A solenidade de inauguração se estendeu à Câmara Municipal onde, em sessão solene, Silva Coelho saudou os representantes do Governo e o senador Azeredo fez um pronunciamento com "frases altamente patrióticas", segundo o jornal.

O Estado encerrou suas atividades já no início de 1915. A partir desse periódico, Rodrigues (1976) fez a listagem de 38 jornais aos quais teve acesso e que circularam em Campo Grande até o ano de 1976. Porém, é natural supor que esse número seja maior, pois um minucioso inventário da imprensa campo-grandense ainda está por ser feito. Dentre os citados pelo autor (1976), vale destacar A Ordem (25/10/1916 a 11/03/1917), como o segundo periódico de Campo Grande. Tinha como diretor L. Babo Júnior e circulava às terças-feiras e aos sábados. Ainda conforme Rodrigues (1976), em substituição à Ordem, em 11 de março de 1917 surgia o Correio do Sul, de propriedade de Antero Paes de Barros, e a 13 de junho seguinte, $O$ Sul, semanário fundado pelo deputado federal Aníbal de Toledo. Nesses dois últimos periódicos, a inscrição "sul” em seus nomes também evidencia que atuavam em defesa dos interesses da região em relação ao restante do estado de Mato Grosso.

O Jornal do Comércio (13/04/1921), que circulou por mais de quarenta anos, foi o jornal de mais longa duração em Campo Grande, até então. Nasceu como semanário e a partir de 14 de abril de 1927 tornou-se o segundo diário da cidade. Propriedade do advogado Jayme Ferreira de Vasconcellos, tinha como redator-chefe Amintas Maciel. Em 1930, foi “empastelado" pelos getulistas exaltados após a Revolução de 30, mas voltou à ativa logo depois de serenados os ânimos. Já próximo ao final de sua trajetória, pertenceu ao Bispado de Campo Grande.

O primeiro diário de Campo Grande foi o Diário do Sul, lançado em 21 de setembro de 1929. Pertencia à Empresa Jornalística Diário do Sul e tinha como diretor o advogado Eduardo Olímpio Machado.

Rubens de Mendonça (1963) avalia que depois de Cuiabá, Corumbá e Campo Grande, a cidade de Três Lagoas foi a que obteve maior desenvolvimento na imprensa de Mato Grosso uno. Assinala que o primeiro jornal local foi a Gazeta do Comércio, lançada a 4 de setembro de 1919. Porém, em seu livro reproduz artigo do jornalista Noginei Pegado, publicado na Gazeta do Comércio em 12 de outubro de 1955 e comemorativo aos 30 anos daquele jornal. No artigo, o jornalista faz um retrospecto da imprensa local e cita a Gazeta de Três Lagoas como o primeiro jornal daquela cidade e 
que circulou de 19 de dezembro de 1915 até 1920. Era dirigida pelo próprio Noginei Pegado, Graça Leite e Antônio Marques, o que permite maior margem de confiabilidade quanto à data exata do início da imprensa em Três Lagoas.

Ainda conforme o artigo, em $1^{\circ}$ de outubro de 1916 foi lançado o Tesoura, que se apresentava como "mordaz, alegórico e arengueiro" e tinha como "comandante J. Guimarães, piloto N. Guimarães e comissário J. Souza”. Na sequência, em maio de 1918, surgiu A Comarca, sob a direção de N. Pinheiro da Silva. O ano de 1919 foi fértil para a imprensa local: foi lançada $A$ Notícia (junho), dirigida por Generoso de Siqueira; A Polyanthea (número único) em homenagem a Dom Aquino Correa; Gazeta do Comércio (12 de outubro), sob a direção de Elmano Soares; O Municipal (9 de dezembro), de Acácio de Castro.

Noginei Pegado enfatiza que a Gazeta do Comércio inaugurou nova fase no jornalismo de Três Lagoas, pois Elmano Soares, vindo de São Paulo, onde atuava em vários jornais, "era um profissional completo e infelizes dos que caíssem na ponta de sua pena afiada e invencível” (apud MENDONÇA, 1975, p. 77). O jornal foi editado até meados dos anos 60 e ao longo da trajetória teve diferentes donatários.

\section{Considerações finais}

Até o final do século XIX, apenas quatro municípios de Mato Grosso uno dispunham de imprensa própria: Cuiabá (1839), Corumbá (1877), Nioaque (1894) e Cáceres (1897), sendo o segundo e o terceiro agora pertencentes ao Mato Grosso do Sul. Foram quase seis décadas para a imprensa alcançar essas cidades. Tal morosidade é compreensível, em razão da grande extensão territorial do estado e das longas distâncias entre os municípios e entre eles e outros importantes centros, como Rio de Janeiro, São Paulo e até mesmo Cuiabá. Em meio à inexistência e/ou à precariedade das estradas, o principal canal de transporte e de comunicação eram os rios, com destaque o Paraguai, Miranda, Aquidauana e Cuiabá, que interligavam Mato Grosso com o Brasil e o mundo. Era por meio dos rios e portos que chegavam e saíam as riquezas, os bens de consumo e culturais, entre os quais a imprensa.

$\mathrm{O}$ reduzido número de jornais naquele período também pode ser atribuído ao pequeno número de municípios: no primeiro censo demográfico realizado no Brasil em 1872, Mato Grosso tinha 37 municípios. Porém, em boa parte das cidades em que havia imprensa, era significativo o número de jornais se consideradas as adversidades da 
época, como o alto índice de analfabetismo, o baixo poder aquisitivo da população, a falta de hábito de leitura, o grande número da população indígena não letrada em português, o pequeno número de habitantes, entre outros fatores estruturais.

Em razão de todos esses fatores políticos, econômicos, sociais e culturais, a história da imprensa de Mato Grosso do Sul ainda está para ser contada em toda sua plenitude e com a consistência necessária. Este breve estudo que denominamos de "apontamentos" esboça apenas alguns indicativos para que outras pesquisas possam desenvolver de forma mais aprofundada.

Submetido em 21.05.2017

Aceito em 28.05.2017

\section{REFERÊNCIAS BIBLIOGRÁFICAS}

ALÉM, Fernando de Castro. O jornal O Progresso e a dinâmica política e eleitoral em Dourados (1954, 1958 e 1962). 2011. 157 f. Dissertação (Programa de Pós-Graduação em História) - Faculdade de Ciências Humanas, Universidade Federal da Grande Dourados (UFGD), Dourados, 2011.

ANDRADE, Danusa Santana. A cobertura dos jornais Correio do Estado, de Campo Grande, e O Estado de Mato Grosso, de Cuiabá, na criação de Mato Grosso do Sul. 2015. 221 f. Dissertação (Programa de Pós-Graduação em Comunicação) - Universidade Federal de Mato Grosso do Sul, Campo Grande, 2015.

ARAKAKI, Suzana. Dourados: memórias e representações de 1964. Dourados: Editora UEMS, 2008.

BAHIA, Juarez. Jornal, história e técnica. Vol. 2. São Paulo: Ática, 1990.

DALMOLIN, José Vicente. O jornal A Voz do Sul 1894. In: Nioaque e as histórias no contexto do Mato Grosso do Sul do século XIX ao XXI. Capítulo XV. 16 abr. 2016a. Disponível em: $<$ http://nioaquehistorias.blogspot.com.br/2016/04/o-jornal-voz-do-sul1894.html >. Acesso em: 23 mar. 2017.

. Nioaque e as raízes dos movimentos da divisão do Estado de Mato Grosso - 1889-

1901. In: Nioaque e as histórias no contexto do Mato Grosso do Sul do século XIX ao XXI. Capítulo XX. 18 abr. 2016b. Disponível em:

$<$ http://nioaquehistorias.blogspot.com.br/2016/04/nioaque-e-as-raizes-dos-movimentosda.html?zx=dc312ed105b39cc7> . Acesso em: 22 mar. 2017.

GAZETA CUYABANA. Cuiabá, p. 1, 2 jun. 1847.

JUCÁ, Pedro Rocha. Exemplo e palavra de jornalista. Em memória do jornalista Archimedes Pereira Lima. Cuiabá: Editora Memórias Cuiabanas, 1995.

. Imprensa Oficial em Mato Grosso. Cuiabá: Imprensa Oficial do Estado, 1986.

MAZINI, André. A história da imprensa no contexto da historiografia brasileira. Revista Comunicação \& Mercado/Unigran, Dourados-MS, v. 01, n. 02, edição especial, p. 297-304, 
nov.

2012.

Disponível

em:

$<$ http://www.unigran.br/mercado/paginas/arquivos/edicoes/1N2/25.pdf $>$. Acesso em: $4 \mathrm{dez}$. $\underline{2016}$.

MELO, José Marques de; DUARTE, Jorge. Memória das Ciências de Comunicação no Brasil: os grupos do Centro-Oeste. Brasília: Uniceub, 2001.

MENDONÇA, Estevão. Datas mato-grossenses. v. 1 e 2. Goiás: Editora Rio Bonito, 1975.

MENDONÇA, Rubens de. História do jornalismo em Mato Grosso. Cuiabá: 1963.

O ESTADO DE MATO GROSSO. Campo Grande, p. 1, jun. 1913.

O ESTADO DE MATO GROSSO. Campo Grande, p. 2 set. 1913.

O ESTADO DE MATO GROSSO. Campo Grande, p. 2 jun. 1914.

PAIS, Luiz Carlos. A Voz do Sul de Nioaque (1894). Recanto das Letras. 16 ago. 2016. Disponível em: <http://www.recantodasletras.com.br/artigos/5730627>. Acesso em: 23 abr. 2017.

RODRIGUES, José Barbosa. O primeiro jornal de Campo Grande. S. ed. 1976.

ZARAMELLA, Sônia. Jornal em Mato Grosso: no começo de tudo, a participação popular. In: ENCONTRO NACIONAL DA REDE ALFREDO DE CARVALHO, 2004, Florianópolis. Anais. Disponível em: <www.ufrgs.br/alcar/encontros-nacionais-1/encontros-nacionais/2oencontro-2004-1/Jornal\%20em\%20Mato\%20Grosso\%20-\%20.doc>. Acesso em: 20 abr. 2017. 